\title{
A microscopic model for the current-voltage behaviour of the Na,K-pump
}

\author{
P. Läuger and H.-J. Apell \\ Department of Biology, University of Konstanz, D-7750 Konstanz, Federal Republic of Germany
}

Received July 5, 1985/Accepted December 2, 1985

\begin{abstract}
The current voltage characteristic of the $\mathrm{Na}, \mathrm{K}$ pump is described on the basis of a modified Post-Albers cycle. The voltage dependence of the rate constants is derived from the elementary chargetranslocations associated with the single reaction steps. Charge displacements result from movements of the sodium- or potassium-loaded binding sites, as well as from motions of polar groups in the pump molecule. If part of the transmembrane voltage drops between the alkali-ion binding sites and the aqueous solution, the binding constants become voltage-dependent. Depending on the values of the microscopic parameters, the current-voltage characteristic may assume a variety of different shapes. Saturating behaviour results when one or more voltage-independent reaction steps become rate limiting. Non-monotonic current-voltage curves exhibiting regions of negative pump conductance are predicted when, at least in one of the transitions, charge is moved against the direction of overall charge-translocation. The theoretical predictions are compared with recent experimental studies of voltage-dependent pump currents.
\end{abstract}

Key words: Na,K-pump, active transport, electrogenic transport, current-voltage behaviour, PostAlbers scheme

\section{Introduction}

The sodium-potassium pump in the plasma membrane of mammalian cells carries out uphill transport of sodium and potassium ions at the expense of free energy of ATP hydrolysis (Skou 1975; Robinson and Flashner 1979; Cantley 1981; Schuurmans et al. 1981; Jørgensen 1982). Since (under normal conditions) in a single turnover three $\mathrm{Na}^{+}$ions are moved outward and two $\mathrm{K}^{+}$ions inward the pump generates a transmembrane electric current. As a consequence of the electrogenic nature of the $\mathrm{Na}, \mathrm{K}$ pump the transport rate becomes a function of membrane voltage. By investigating the voltage dependence of the pump current, information on the transport mechanism may be obtained (Hansen et al. 1981; Gradmann et al. 1982; Chapman et al. 1983; De Weer 1984; Glynn 1984; Läuger 1984). Experimental studies of voltage effects on the activity of the $\mathrm{Na}, \mathrm{K}$ pump could be performed in the past only in a narrow voltage interval (Hodgkin and Keynes 1955; Nakajima and Takahashi 1966; Meunier and Tauc 1970; Isenberg and Trautwein 1974; Zade-Oppen et al. 1979; Eisner and Lederer 1980; Glitsch et al. 1982; Gadsby 1984; Lederer and Nelson 1984). More recently, by using the whole-cell recording technique with patch pipettes it has become possible to measure the current-voltage characteristic in a more extended voltage range (Gadsby et al. 1985).

A pump cycle involves a series of conformational changes which are induced by phosphorylationdephosphorylation reactions and which are coupled to binding of ions from one side of the membrane and release to the other. In principle, any step in the cycle can be affected by the electrical field. The voltage dependence of a given rate constant is a function of the charge translocated in the corresponding transition. Charge translocation may result from binding of an ion from the aqueous medium to a binding site buried in the membrane dielectric, from a movement of the ion together with the binding site, or from a rotation of dipolar groups of the protein in the course of a conformational transition.

In the following, the influence of an electric field on the reaction steps of the pump cycle are treated using a microscopic model. Such an analysis enables one to predict the shape of the current-voltage characteristic of the transport system from the voltage dependence of the individual reaction rate constants. Conversely, from the experimentally observed current-voltage curve inferences can be made on the mechanism of charge translocation by the pump. 


\section{The pumping cycle: basic assumptions}

The analysis which is given below is based on the Post-Albers scheme of the pumping cycle (Cantley 1981; Cantley et al. 1984). According to the PostAlbers model (Fig. 1), which is supported by many experimental findings, the enzyme can assume two conformations, $E_{1}$ and $E_{2}$. Form $E_{1}$ which has the ion-binding sites exposed to the cytoplasmic side of the membrane can be phosphorylated after binding of three $\mathrm{Na}^{+}$ions (forward direction of the pumping cycle in Fig. 1). In the phosphorylated state, $E_{1}-P$, the $\mathrm{Na}^{+}$ions are "occluded", i.e., they are unable to exchange with one or the other aqueous phase (Glynn et al. 1984). The occluded form, $\left(\mathrm{Na}_{3}\right) \mathrm{E}_{1}-\mathrm{P}$, undergoes a conformation transition to a state $\mathrm{P}-\mathrm{E}_{2} \cdot \mathrm{Na}_{3}$ in which the ion binding sites are acessible from the external medium; in addition, the ion specificity is changed in such a way that $\mathrm{Na}^{+}$is released and $\mathrm{K}^{+}$is preferentially bound. The potassium form, $\mathrm{P}-\mathrm{E}_{2} \cdot \mathrm{K}_{2}$, then becomes dephosphorylated, possibly via an intermediate with non-covalently bound inorganic phosphate $\left(\mathrm{P}_{i}\right)$. The cycle is completed by the transition from state ATP $\cdot \mathrm{E}_{2}\left(\mathrm{~K}_{2}\right)$ with occluded potassium to state ATP $\cdot E_{1} \cdot K_{2}$, followed by release of $\mathrm{K}^{+}$to the cytoplasm and rebinding of $\mathrm{Na}^{+}$.

As indicated in Fig. 1, the reaction rates are described by rate constants $p_{f}, l_{f}, q_{f}, s_{f} c_{T}, k_{f}$ for transi-

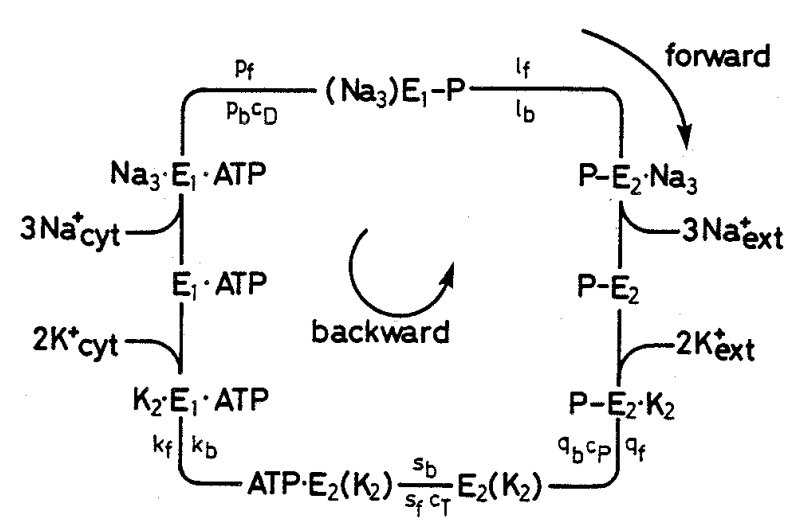

Fig. 1. Post-Albers scheme for the pumping cycle of $\mathrm{Na}, \mathrm{K}$ ATPase (adapted from Cantley et al. 1984). $E_{1}$ and $E_{2}$ are conformations of the enzyme with ion binding sites exposed to the cytoplasm and the extracellular medium, respectively. In the "occluded" states $\left(\mathrm{Na}_{3}\right) \mathrm{E}_{1}$ and $\mathrm{E}_{2}\left(\mathrm{~K}_{2}\right)$ the bound ions are unable to exchange with the aqueous phase. Dashes indicate covalent bonds and dots indicate noncovalent bonds. $p_{f}, l_{f}$, $q_{f}, s_{f} c_{T}, k_{f}$ and $p_{b} c_{D}, k_{b}, s_{b}, q_{b} c_{P}, l_{b}$ are rate constants for transitions in forward and backward direction, respectively. $c_{T}, c_{D}$ and $c_{P}$ are the cytoplasmic concentrations of ATP, ADP and $\mathrm{P}_{i}$ (inorganic phosphate). It is assumed that $c_{T}$ is high $(\gtrsim 0.1 \mathrm{~m} M)$ so that transitions $\mathrm{E}_{2}\left(\mathrm{~K}_{2}\right) \leftrightarrow \mathrm{K}_{2} \cdot \mathrm{E}_{1}$ without bound ATP are of minor importance (Cantley et al. 1984) tions in the forward direction and by rate constants $p_{b} c_{D}, k_{b}, s_{b}, q_{b} c_{P}, l_{b}$ for transitions in the backward direction; $c_{T}, c_{D}$ and $c_{P}$ are the cytoplasmic concentrations of ATP, ADP and $\mathrm{P}_{i}$, respectively. In the notation adopted here the bimolecular reaction $\left(\mathrm{Na}_{3}\right) \mathrm{E}_{1}-\mathrm{P}+\mathrm{ADP} \rightarrow \mathrm{Na}_{3} \cdot \mathrm{E}_{1} \cdot \mathrm{ATP}$ is described by a pseudo-monomolecular rate constant $p_{b} c_{D}$; the rate constants $q_{b} c_{P}$ and $s_{f} c_{T}$ are defined in an analogous way.

We assume that the enzyme in both conformations $\left(E_{1}\right.$ and $\left.E_{2}\right)$ can bind up to three $\mathrm{Na}^{+}$ions or up to two $\mathrm{K}^{+}$ions. This means that $\mathrm{E}_{j}(j=1,2)$ can occur in the following forms: $\mathrm{Na}_{3} \mathrm{E}_{j}, \mathrm{Na}_{2} \mathrm{E}_{j}, \mathrm{NaE}_{j}$, $\mathrm{E}_{j}, \mathrm{KE}_{j}$ and $\mathrm{K}_{2} \mathrm{E}_{j}$. Mixed species such as $\mathrm{NaE}_{j} \mathrm{~K}$ are excluded, and the three $\mathrm{Na}^{+}$sites (and also the two $\mathrm{K}^{+}$sites) are considered to be equivalent. We further assume that the rate constants for binding and release of $\mathrm{Na}^{+}$and $\mathrm{K}^{+}$are large, so that the six different forms are always in equilibrium with each other. This assumption is amply justified when binding from the aqueous phase is diffusion-controlled (rate constants, $k_{\text {on }}$, of ion binding $\sim 10^{9} \mathrm{M}^{-1} \mathrm{~s}^{-1}$ ). In this case the binding rate $c \cdot k_{\text {on }}$ is at least $10^{6} \mathrm{~s}^{-1}$ for ion concentrations $c>1 \mathrm{~m} M$ and the dissociation rate $k_{\text {off }}$ is at least $10^{5} \mathrm{~s}^{-1}$, assuming a lower limit for the equilibrium dissociation constant, $k_{\text {off }} / k_{\text {on }}$, of $0.1 \mathrm{~m} M$. While binding rates of alkali ions to oxygen ligands are usually very large and close to the limit of diffusion-controlled reactions (Eigen and Maass 1966), direct experimental information on binding rate constants in the case of the $\mathrm{Na}, \mathrm{K}$-ATPase is lacking. The assumption of fast binding/dissociation is introduced here mainly for simplicity; it can be replaced by a more refined treatment as soon as more detailed experimental data become available. If $c_{N}^{\prime}$ is the $\mathrm{Na}^{+}$concentration on the cytoplasmic side and $x[A]$ the fraction of $\mathrm{Na}, \mathrm{K}$-ATPase present in form $A, \mathrm{Na}^{+}$binding at the cytoplasmic side is then described by

$$
\begin{aligned}
& \frac{x\left[\mathrm{E}_{1} \cdot \mathrm{ATP}\right]}{x\left[\mathrm{Na} \cdot \mathrm{E}_{1} \cdot \mathrm{ATP}\right]}=\frac{\mathrm{K}_{N 1}^{\prime}}{c_{N}^{\prime}} \\
& \frac{x\left[\mathrm{Na} \cdot \mathrm{E}_{1} \cdot \mathrm{ATP}\right]}{x\left[\mathrm{Na}_{2} \cdot \mathrm{E}_{1} \cdot \mathrm{ATP}\right]}=\frac{\mathrm{K}_{N 2}^{\prime}}{c_{N}^{\prime}} \\
& \frac{x\left[\mathrm{Na}_{2} \cdot \mathrm{E}_{1} \cdot \mathrm{ATP}\right]}{x\left[\mathrm{Na}_{3} \cdot \mathrm{E}_{1} \cdot \mathrm{ATP}\right]}=\frac{\mathrm{K}_{N 3}^{\prime}}{c_{N}^{\prime}}
\end{aligned}
$$

$\mathrm{K}_{N 1}^{\prime}, \mathrm{K}_{N 2}^{\prime}$ and $\mathrm{K}_{N 3}^{\prime}$ are the equilibrium dissociation constants of $\mathrm{Na}^{+}$at the cytoplasmic site. Analogous equations hold for the other binding equilibria.

According to the principle of microscopic reversibility (or detailed balance) the rate constants and equilibrium constants of the cycle are not independent of each other but are connected by the following 
relation (Appendix A):

$$
\begin{array}{r}
\frac{p_{f} l_{f} q_{f} s_{f} c_{T} k_{f}}{p_{b} c_{D} k_{b} s_{b} q_{b} c_{P} l_{b}} \cdot \frac{\mathrm{K}_{N 1}^{\prime \prime} \mathrm{K}_{N 2}^{\prime \prime} \mathrm{K}_{N 3}^{\prime \prime}}{\mathrm{K}_{N 1}^{\prime} \mathrm{K}_{N 2}^{\prime} \mathrm{K}_{N 3}^{\prime}} \cdot \frac{\mathrm{K}_{K 1}^{\prime} \mathrm{K}_{K 2}^{\prime}}{\mathrm{K}_{K 1}^{\prime \prime} \mathrm{K}_{K 2}^{\prime \prime}} \\
=\exp (u-\Delta G / R T),
\end{array}
$$

$\Delta G$ is the free energy of ATP hydrolysis:

$\Delta G=R T \ln \frac{c_{D} c_{P} / c_{T}}{\tilde{c}_{D} \bar{c}_{P} / \bar{c}_{T}}$

where $R$ is the gas constant, $T$ the absolute temperature and $\bar{c}_{T}, \bar{c}_{D}$ and $\bar{c}_{P}$ are equilibrium concentrations of ATP, ADP and $\mathrm{P}_{i}$, respectively. The membrane voltage, $u$, is defined as the difference of the electrical potential $\psi^{\prime}$ in the cytoplasm and the electrical potential $\psi^{\prime \prime}$ in the extracellular medium and is expressed in dimensionless units of $\mathrm{kT} / e_{0} \simeq 25 \mathrm{mV}$ ( $\mathrm{k}$ is the Boltzmann constant and $e_{0}$ the elementary charge):

$$
u \equiv \frac{V}{\mathrm{kT} / e_{0}} \equiv \frac{\psi^{\prime}-\psi^{\prime \prime}}{\mathrm{kT} / e_{0}}
$$

\section{Voltage dependence of kinetic parameters}

In order to describe the voltage dependence of the kinetic parameters we introduce the energy profile of the ion along the transport pathway (Parlin and Eyring 1954). The energy profile consists of a series of barriers and wells (Fig. 2); it reflects the interaction of the ion with the protein in a particular conformation (Warshel and Russel 1984). According to the assumption of a fast association-dissociation equilibrium, the ion-binding site in state $\mathrm{Na}_{3} \cdot \mathrm{E}_{1} \cdot \mathrm{ATP}$ is connected with the cytoplasmic side by a series of low barriers (Fig. 2); the site is separated from the extracellular medium by a high barrier.

If an electrical potential difference, $u$, exists between the cytoplasm and the extracellular solution (Eq. (6)), a fraction $\alpha^{\prime} u$ drops between the cytoplasm and the binding site (Fig. 2). The (dimensionless) quantity $\alpha^{\prime}\left(0 \leq \alpha^{\prime} \leq 1\right)$ depends on the location of the binding site within the protein as well as on the dielectric properties of the protein and the surrounding medium. (Since the protein may protrude from the membrane into the aqueous phase, the dielectric distance across with the voltage $u$ drops is not necessarily identical with the membrane thickness.) As the potential energy of an ion in the binding site is modified by the presence of a voltage $u$, the equilibrium dissociation constants $\mathrm{K}_{N 1}^{\prime}, \mathrm{K}_{N 2}^{\prime}$, and $\mathrm{K}_{N 3}^{\prime}$ (Eqs. (1) - (3)) become voltage-dependent:

$\mathrm{K}_{N 1}^{\prime}=\tilde{\mathrm{K}}_{N 1}^{\prime} \exp \left(-\alpha^{\prime} u\right)$

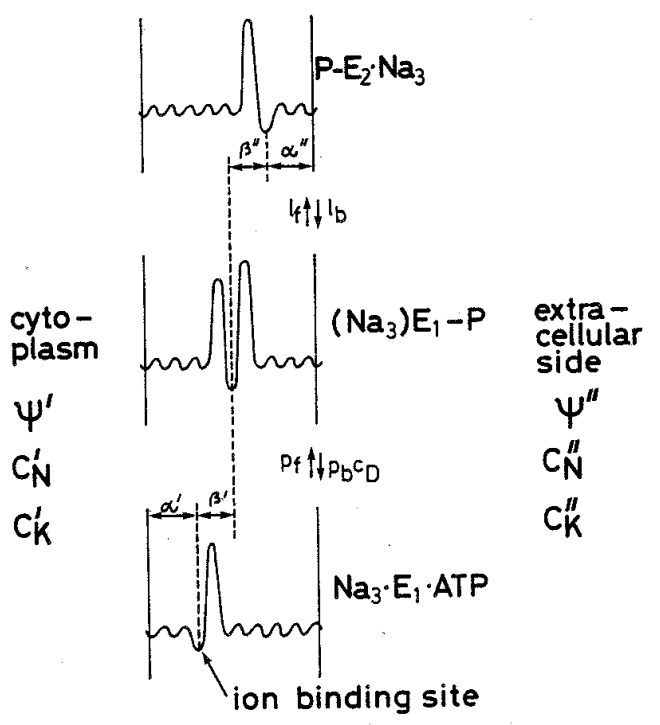

Fig. 2. Energy profile of a sodium ion along the transport pathway. According to the assumptions discussed in the text, the ion binding sites in state $\mathrm{Na}_{3} \cdot \mathrm{E}_{1} \cdot \mathrm{ATP}$ are connected with the cytoplasmic side by a series of low barriers, but separated from the extracellular medium by a high barrier. In the "occluded" state $\left(\mathrm{Na}_{3}\right) \mathrm{E}_{1} \sim \mathrm{P}$ the energy barriers on either side are high. In state $\mathrm{P}-\mathrm{E}_{2} \cdot \mathrm{Na}_{3}$ the binding sites are easily accessible from the extracellular phase. $\psi^{\prime}$ and $\psi^{\prime \prime}$ are the electrical potentials in the cytoplasm and in the extracellular medium, respectively, $c_{N}^{\prime}, c_{N}^{\prime \prime}$ are the concentrations of sodium and $c_{K}^{\prime}, c_{K}^{\prime \prime}$ the concentrations of potassium. $\alpha^{\prime} V$ is the fraction of total voltage $V=\psi^{\prime}-\psi^{\prime \prime}$ which drops between cytoplasm and ion binding site; $\alpha^{\prime \prime}, \beta^{\prime}$ and $\beta^{\prime \prime}$ are defined in an analogous way. The (dimensionless) quantities $\alpha^{\prime}, \alpha^{\prime \prime}, \beta^{\prime}$ and $\beta^{\prime \prime}$ depend on the location of the binding site in the protein as well as on the dielectric properties of the protein and the surrounding medium. The direction of the ion pathway in the protein may be different from the direction of the external field; the potential profile then refers to the projection of the transport pathway onto the field direction

where $\tilde{\mathrm{K}}_{N 1}^{\prime}$ is the value of $\mathrm{K}_{N 1}^{\prime}$ at zero voltage. If the potential of the cytoplasm is positive with respect to the external medium $(u>0)$, the equilibrium constant $1 / \mathrm{K}_{N 1}^{\prime}$ of sodium binding is increased by the Boltzmann factor $\exp \left(\alpha^{\prime} u\right)$. The binding site acts as an "ion well" (Mitchell and Moyle 1974), i.e., a change of electrical potential has a similar effect on the occupancy of the site as a change of external concentration. Assuming that the three sodium sites are equivalent and that potassium binds to the same sites on $E_{1}$ as sodium, analogous expressions (with the same electrostatic coefficient $\alpha^{\prime}$ ) are obtained for $\mathrm{K}_{N 2}^{\prime}, \mathrm{K}_{N 3}^{\prime}, \mathrm{K}_{K 1}^{\prime}$ and $\mathrm{K}_{K 2}^{\prime}$. If $\alpha^{\prime \prime} u$ is the potential at the binding site in state $E_{2}$ with respect to the extracellular medium (Fig. 2), the voltage dependence of $\mathrm{K}_{K 1}^{\prime \prime}$ is given by

$\mathrm{K}_{K 1}^{\prime \prime}=\tilde{\mathrm{K}}_{K 1}^{\prime \prime} \exp \left(\alpha^{\prime \prime} u\right)$. 
Analogous expressions hold for $\mathrm{K}_{K 2}^{\prime \prime}, \mathrm{K}_{N 1}^{\prime \prime}, \mathrm{K}_{N 2}^{\prime \prime}$ and $\mathrm{K}_{N 3}^{\prime \prime}$.

In the process $\mathrm{Na}_{3} \cdot \mathrm{E}_{1} \cdot \mathrm{ATP} \rightarrow\left(\mathrm{Na}_{3}\right) \mathrm{E}_{1}-\mathrm{P}$ the protein is phosphorylated and the bound sodium ions become occluded. This transition is, in general, associated with a conformational change whereby the bound ions together with the ligand groups move over a certain distance. The effective dielectric distance over which the binding sites are translocated is described by a phenomenological parameter, $\beta^{\prime}$ (Fig. 2). The electrostatic contribution of ions plus binding sites to the energy difference between states $\mathrm{Na}_{3} \cdot \mathrm{E}_{1} \cdot \mathrm{ATP}$ and $\left(\mathrm{Na}_{3}\right) \mathrm{E}_{1}-\mathrm{P}$ may be written as $\left(3+z_{L}\right) \beta^{\prime} u$ where $z_{L} e_{0}$ is the charge of the empty ligand system; the energy is expressed in units of $\mathrm{kT}$. If in the transition intrinsic charges of the protein (other than charged ligands) are translocated, an additional energy contribution of magnitude $\eta^{\prime} u$ results. $\eta^{\prime}$ is given by the relation (Läuger 1984):

$\eta^{\prime}=\sum q_{i} \Delta x_{i} / e_{0} d$,

where $\Delta x_{i}$ is the displacement of charge $q_{i}$ in the direction of the external field and $d$ is the length over which the external voltage drops in the pump molecule. We assume, as an approximation, that the process $\mathrm{Na}_{3} \cdot \mathrm{E}_{1} \cdot \mathrm{ATP} \rightarrow\left(\mathrm{Na}_{3}\right) \mathrm{E}_{1}-\mathrm{P}$ takes place in a single step which may be described as a transition over a symmetrical, narrow activation barrier (Läuger 1984). According to the theory of absolute reaction rates (Glasstone et al. 1941) the forward and backward rate constants are then given by

$p_{f}=\tilde{p}_{f} \exp \left\{\left[\left(3+z_{L}\right) \beta^{\prime}+\eta^{\prime}\right] u / 2\right\}$,

$p_{b}=\tilde{p}_{b} \exp \left\{-\left[\left(3+z_{L}\right) \beta^{\prime}+\eta^{\prime}\right] u / 2\right\}$.

In a completely analogous way one obtains for the other forward rate constants:

$l_{f}=\tilde{l}_{f} \exp \left\{\left[\left(3+z_{L}\right) \beta^{\prime \prime}+\eta^{\prime \prime}\right] u / 2\right\}$,

$q_{f}=\tilde{q}_{f} \exp \left\{\left[\left(2+z_{L}\right) \gamma^{\prime \prime}+\theta^{\prime \prime}\right] u / 2\right\}$,

$k_{f}=\tilde{k}_{f} \exp \left\{\left[\left(2+z_{L}\right) \gamma^{\prime}+\theta^{\prime}\right] u / 2\right\}$,

where $\beta^{\prime \prime}, \eta^{\prime \prime}, \gamma^{\prime}, \gamma^{\prime \prime}, \theta^{\prime}$ and $\theta^{\prime \prime}$ are "dielectric coefficients" defined in an analogous way to $\beta^{\prime}$ and $\eta^{\prime}$. The corresponding backward rate constants are obtained from Eqs. (11)-(13) by changing the sign of the exponent. For simplicity we have assumed that the rate constants $s_{f}$ and $s_{b}$ describing binding and release of ATP in state $E_{2}\left(K_{2}\right)$ are voltage-independent.

In the (hypothetical) process $\mathrm{Na}_{\text {cyt }}^{+}+\mathrm{E}_{1} \cdot \mathrm{ATP} \rightarrow$ $\mathrm{Na} \cdot \mathrm{E}_{1} \cdot \mathrm{ATP} \rightarrow(\mathrm{Na}) \mathrm{E}_{1}-\mathrm{P} \rightarrow \mathrm{P}-\mathrm{E}_{2} \cdot \mathrm{Na} \rightarrow \mathrm{P}-\mathrm{E}_{2}$ $+\mathrm{Na}_{\text {ext }}^{+}$a sodium ion is translocated from the cytoplasm to the extracellular medium. The change of electrostatic energy associated with this process is the sum of the contributions of all single steps and is equal to (in units of kT): $-\alpha^{\prime} u-\beta^{\prime} u-\beta^{\prime \prime} u-\alpha^{\prime \prime} u$
(Fig. 2). This sum must be equal to $-u$, the electrostatic energy required for the translocation of a univalent cation across the membrane. This means that the following relation holds:

$\alpha^{\prime}+\alpha^{\prime \prime}+\beta^{\prime}+\beta^{\prime \prime}=1$.

A similar argument applies to the translocation of a potassium ion in the sequence $\mathrm{K}_{\text {ext }}^{+}+\mathrm{P}-\mathrm{E}_{2} \rightarrow \cdots \rightarrow$ $\mathrm{E}_{1} \cdot \mathrm{ATP}+\mathrm{K}_{\text {cyt }}^{+}$, yielding

$\gamma^{\prime}+\gamma^{\prime \prime}-\alpha^{\prime}-\alpha^{\prime \prime}=-1$.

Furthermore, when the enzyme goes through the complete cycle of conformational transitions (Fig. 1) the sum of all intrinsic charge displacements must be zero. This means that

$\eta^{\prime}+\eta^{\prime \prime}+\theta^{\prime}+\theta^{\prime \prime}=0$.

According to Eqs. (14) $-(16)$ only 7 of a total of 10 dielectric coefficients $\alpha^{\prime}, \alpha^{\prime \prime}, \ldots$ are independent.

Implicit in the derivation of Eqs. (14)-(16) is the assumption that charge displacements by translocation of $\mathrm{Na}^{+}$and $\mathrm{K}^{+}$can be completely separated from charge displacements associated with motions of polar groups of the protein itself. This assumption does not hold when, for instance, the binding of a sodium ion leads to a major rearrangement of dipolar groups in the protein. In the most general case only a single relation exists between the dielectric coefficients which follows directly from Eq. (14) and which has the form $\varepsilon_{p}+\varepsilon_{l}+\varepsilon_{r}+\varepsilon_{k}+\alpha^{\prime}+\alpha^{\prime \prime}=1$ where $\varepsilon_{p} \equiv\left(3+z_{L}\right) \beta^{\prime}+\eta^{\prime}, \varepsilon_{l} \equiv\left(3+z_{L}\right) \beta^{\prime \prime}+\eta^{\prime \prime}$, etc. In principle, as seen from Eqs. (7)-(13), the coefficients $\varepsilon_{p}, \varepsilon_{l}, \varepsilon_{r}, \varepsilon_{k}, \alpha^{\prime}$ and $\alpha^{\prime \prime}$ are sufficient to describe the voltage dependence of pumping rate; however, for a better insight into the origin of the field effects it seems preferable to separate contributions from alkali-ion movements and contributions from movements of polar groups of the protein.

\section{Numerical values of kinetic parameters}

For some of the rate constants of the pumping cycle (Fig. 1) numerical values can be estimated on the basis of experimental data from the literature. A difficulty, however, results from the diversity of preparations used in the experiments with the $\mathrm{Na}, \mathrm{K}$ pump. For electrophysiological measurements of ion fluxes and pump currents, squid axons, mammalian heart cells or barnacle muscle fibres have been used, whereas kinetic studies of ATPase activity have been done mainly with erythrocytes or with enzyme preparations from various sources such as kidney or brain. So far it is now known to what extent the kinetic properties of Na,K-ATPases of different origin are comparable and therefore the assignment of rate constants for the calculation of pump currents is tentative. In Table 1 we give a list of values 
Table 1. Numerical values of kinetic parameters (Fig. 1) used in the calculation of current-voltage curves

\begin{tabular}{lrl}
\hline Parameter & Value & Notes \\
\hline$\tilde{p}_{f}$ & $270 \mathrm{~s}^{-1}$ & $\mathrm{a}$ \\
$\tilde{p}_{b} c_{D}$ & $2 \mathrm{~s}^{-1}$ & $c_{D}=0.1 \mathrm{~m} M^{\mathrm{b}}$ \\
$\tilde{l}_{f}$ & $120 \mathrm{~s}^{-1}$ & $\mathrm{c}$ \\
$\tilde{l}_{b}$ & $10 \mathrm{~s}^{-1}$ & $\mathrm{~d}$ \\
$\tilde{q}_{f}$ & $500 \mathrm{~s}^{-1}$ & $\mathrm{e}$ \\
$\tilde{q}_{b} c_{P}$ & $5,000 \mathrm{~s}^{-1}$ & $c_{P}=5 \mathrm{~m} M^{\mathrm{e}}$ \\
$\tilde{s}_{f} c_{T}$ & $5,000 \mathrm{~s}^{-1}$ & $c_{T}=5 \mathrm{~m} M^{\mathrm{f}}$ \\
$\tilde{s}_{b}$ & $110 \mathrm{~s}^{-1}$ & $f$ \\
$\tilde{k}_{f}$ & $80 \mathrm{~s}^{-1}$ & $\mathrm{~g}$ \\
$\tilde{k}_{b}$ & $10 \mathrm{~s}^{-1}$ & $\mathrm{~g}$ \\
$\tilde{\mathrm{K}}_{N}^{\prime}$ & $4 \mathrm{~m} M$ & see text \\
$\tilde{\mathrm{K}}_{N}^{\prime \prime}$ & $100 \mathrm{~m} M$ & see text \\
$\tilde{\mathrm{K}}_{K}^{\prime}$ & $8 \mathrm{~m} M$ & see text \\
$\tilde{\mathrm{K}}_{K}^{\prime \prime}$ & $2 \mathrm{~m} M$ & see text \\
$\tilde{c}_{N}^{\prime}$ & $10 \mathrm{~m} M$ & Mullins (1981) \\
$c_{N}^{\prime \prime}$ & $140 \mathrm{~m} M$ & Mullins (1981) \\
$c_{K}^{\prime}$ & $150 \mathrm{~m} M$ & Mullins (1981) \\
$c_{K}^{\prime \prime}$ & $5 \mathrm{~m} M$ & Mullins (1981) \\
$\Delta G$ & $-58 \mathrm{~kJ} / \mathrm{mol}$ & Veech et al. (1979) \\
\hline
\end{tabular}

All values refer to zero voltage and a temperature of $25^{\circ} \mathrm{C}$. $c_{T}, c_{D}, c_{P}$ : cytoplasmic concentrations of ATP, ADP and $\mathrm{P}_{i}$, respectively; $c_{N}^{\prime}, c_{K}^{\prime}$ : cytoplasmic concentrations of $\mathrm{Na}^{+}$and $\mathrm{K}^{+} ; c_{N}^{\prime \prime}, c_{K}^{\prime \prime}$ : extracellular concentrations of $\mathrm{Na}^{+}$and $\mathrm{K}^{+}$. $\tilde{\mathrm{K}}_{N}^{\prime}, \widetilde{\mathrm{K}}_{K}^{\prime}$ : equilibrium dissociation constants of $\mathrm{Na}^{+}$and $\mathrm{K}^{+}$ in state $E_{1}$ of the enzyme; $\tilde{\mathrm{K}}_{\mu}^{\prime \prime}, \tilde{\mathrm{K}}_{\mathrm{K}}^{\prime \prime}$ : dissociation constants in state $\mathrm{E}_{2}$.

a Mårdh and Zetterquist (1974) obtained, at $21^{\circ} \mathrm{C}$, a value of $180 \mathrm{~s}^{-1}$ for the pseudo-first-order rate constant of phosphorylation of bovine brain microsomal $\mathrm{Na}, \mathrm{K}$-ATPase when neither $\mathrm{Na}^{+}$nor ATP were rate-limiting

b Mårdh (1975) studied the dephosphorylation rate of $E_{1}-P$ with bovine brain enzyme in the presence of $120 \mathrm{mM} \mathrm{Na}^{+}$ after rapid mixing with a high concentration $\left(c_{D}=5 \mathrm{mM}\right)$ of ADP. From Fig. 6 of Mårdh's paper a value of $20 \mathrm{~s}^{-1}$ for the pseudo first-order dephosphorylation rate constant may be estimated (at $21^{\circ} \mathrm{C}$ and $c_{D}=5 \mathrm{mM}$ ), corresponding to $p_{b} c_{D} \simeq 30 \mathrm{~s}^{-1}$ at $25^{\circ} \mathrm{C}$. Under physiological conditions the
ADP concentration is much lower than $5 \mathrm{mM}$, of the order of $0.1 \mathrm{~m} M$ (Veech et al. 1979). If the dephosphorylation rates were linearly related to $c_{D}$, the value of $\tilde{p}_{b} c_{D}$ at $c_{D}=0.1 \mathrm{~m} M$ would be $0.6 \mathrm{~s}^{-1}$. However, since the dephosphorylation of $\left(\mathrm{Na}_{3}\right) \mathrm{E}_{1}-\mathrm{P}$ by ADP is likely to be a two-step process consisting of a bimolecular binding step followed by a monomolecular dephosphorylation reaction, the rate of dephosphorylation may already be saturated with respect to $c_{D}$ at $c_{D} \leq 5 \mathrm{~m} M$. For this reason a somewhat higher value, $\tilde{p}_{b} c_{D} \simeq 2 \mathrm{~s}^{-1}$, is used as an estimate for the dephosphorylation rate constant

c In the presence of $10 \mathrm{mMK} \mathrm{K}^{+}$, when the transition $\left(\mathrm{Na}_{3}\right) \mathrm{E}_{1}-\mathrm{P}$ $\rightarrow \mathrm{P}-\mathrm{E}_{2} \cdot \mathrm{Na}_{3}$ is thought to be rate limiting, Mårdh (1975) obtained a rate constant of $77 \mathrm{~s}^{-1}$ at $21^{\circ} \mathrm{C}$ for the dephosphorylation of the $\mathrm{K}^{+}$-sensitive form of the phosphoenzyme. With $Q_{10} \simeq 2.6$ this gives $\tilde{l}_{f} \simeq 120 \mathrm{~s}^{-1}$

d From the experiments of Mårdh (1975), Glynn et al. (1984) calculated a rate of $3.8 \mathrm{~s}^{-1}$ for the transition $\mathrm{P}-\mathrm{E}_{2} \cdot \mathrm{Na}_{3}$ $\rightarrow\left(\mathrm{Na}_{3}\right) \mathrm{E}_{1}-\mathrm{P}$ at a (non-saturating) $\mathrm{Na}^{+}$concentration of $120 \mathrm{mM}\left(21^{\circ} \mathrm{C}\right)$. Using Garay and Garrahan's (1973) data on $\mathrm{Na}-\mathrm{Na}$ exchange in erythrocytes, Glynn et al. (1984) estimated that the rate at high sodium concentration may be about twice as large. With $Q_{10} \simeq 2.6$, a value of $\tilde{l}_{b}$ of about $10 \mathrm{~s}^{-1}$ is obtained

e These values have been arbitrarily introduced assuming that the reaction $P \cdot E_{2} \cdot K_{2} \leftrightarrow E_{2}\left(K_{2}\right)$ is not rate limiting. A ratio $\tilde{q}_{b} c_{p} / \tilde{q}_{f}$ of 10 has been chosen in order to obtain a reasonable value for $\tilde{s}_{b}$ from Eq. (4)

f The value of $\tilde{s}_{f} c_{T}$ was arbitrarily set at $5,000 \mathrm{~s}^{-1}$ assuming that ATP binding to $E_{2}\left(\mathrm{~K}_{2}\right)$ is not rate limiting at physiological ATP levels $\left(c_{T} \simeq 5 \mathrm{mM}\right)$. The rate constant $\tilde{s}_{b}$ was calculated from Eq. (4) for $u=0$ and $\Delta G=-58 \mathrm{~kJ} / \mathrm{mol}$ (Veech et al. 1979; Tanford 1981) using the values of the other kinetic parameters as given in Table 1. The ratio $\tilde{s}_{b} / \tilde{s}_{f} \simeq 0.11 \mathrm{~m} M$ is consistent with estimated values of $0.1-1 \mathrm{~m} M$ for the equilibrium dissociation constant of ATP in state $E_{2}$ of the enzyme (Robinson and Flashner 1979; Moczydlowski and Fortes 1981; Reynolds et al. 1985)

g The value of $\bar{k}_{f}$ is taken from Karlish and Yates (1978) who estimated for the transition $E_{2}\left(K_{2}\right) \rightarrow K_{2} \cdot E_{1}$ a rate of about $50 \mathrm{~s}^{-1}$ from stopped-flow experiments at $20^{\circ} \mathrm{C}$ and saturating ATP concentrations. For the rate of the reverse transition Karlish (1980) observed a value of $290 \mathrm{~s}^{-1}$ in the absence of $\mathrm{Mg}^{++}$and nucleotides. Glynn and Richards (1982), however, pointed out that $\tilde{k}_{b}$ may be much smaller in the presence of $\mathrm{Mg}^{++}$and ATP and estimated a value of the order of $10 \mathrm{~s}^{-1}$ under physiological conditions of kinetic parameters which have been used in the numerical evaluation of current-voltage curves described in the next sections. All values refer to zero voltage and a temperature of $25^{\circ} \mathrm{C}$; if necessary, rate constants measured at other temperatures have been corrected using (as a crude approximation) the activation energy of the overall $\mathrm{Na}, \mathrm{K}$-ATPase activity $\left(\mathrm{E}_{a} \simeq 71 \mathrm{~kJ} / \mathrm{mol}\right.$, corresponding to $\left.Q_{10} \simeq 2.6\right)$ (Post et al. 1965).

In addition to the rate constants listed in Table 1 the equilibrium dissociation constants for sodium and potassium are required for the calculation of transport rates. Experimental information on binding of $\mathrm{Na}^{+}$and $\mathrm{K}^{+}$to the enzyme is scanty so far. Values of dissociation constants have been determined from binding studies (Kaniike et al. 1976;
Matsui et al. 1977; Hastings and Skou 1980; Yamaguchi et al. 1983), but the functional role of the binding sites revealed in these experiments remains unclear. For the numerical evaluation of currentvoltage curves we have chosen a set of binding constants which approximately describe the observed dependence of ATPase activity on the concentrations of $\mathrm{Na}^{+}$and $\mathrm{K}^{+}$(Chapman et al. 1983). Assuming that the three sodium sites, and also the two potassium sites, of the reaction cycle (Fig. 1) are identical and independent (Robinson 1983), the following relations are obtained for the equilibrium dissociation constants $\mathrm{K}_{N 1}^{\prime}, \mathrm{K}_{N 2}^{\prime}, \ldots$ :

$$
\begin{array}{ll}
\mathrm{K}_{N 1}^{\prime}=\frac{1}{3} \mathrm{~K}_{N}^{\prime} ; \quad \mathrm{K}_{N 2}^{\prime}=\mathrm{K}_{N}^{\prime} ; \quad \mathrm{K}_{N 3}^{\prime}=3 \mathrm{~K}_{N}^{\prime} \\
\mathrm{K}_{K 1}^{\prime}=\frac{1}{2} \mathrm{~K}_{K}^{\prime} ; \quad \mathrm{K}_{K 2}^{\prime}=2 \mathrm{~K}_{K}^{\prime}
\end{array}
$$


where $\mathrm{K}_{N}^{\prime}$ and $\mathrm{K}_{K}^{\prime}$ are the intrinsic dissociation constants of the binding sites in state $E_{1}$. The factors $1 / 3,3,1 / 2$ and 2 are the usual statistical coefficients describing binding equilibria in a system with multiple binding sites (Tanford 1961). Analogous relations hold for the dissociation constants in state $E_{2}$. Equations (17) and (18) represent a gross simplification; for a more elaborate treatment of alkali-ion binding to the $\mathrm{Na}, \mathrm{K}$-pump, see Karlish and Stein (1985). The predicted hydrolysis rate, $v$, of ATP as a function of molar fraction of $\mathrm{Na}^{+}$is shown in Fig. 3 for an experiment in which the total alkali-ion concentration (sodium plus potassium) has been held constant (Skou 1975). For the calculation the numerical values of the rate constants and equilibrium constants given in Table 1 have been used. As seen from Fig. 3, the theoretical values of $v$ reproduce the shape of the experimental curve only qualitatively. A much better fit can be obtained using a larger value of the dissociation constant of $\mathrm{Na}^{+}$at the cytoplasmic side $\left(\mathrm{K}_{N}^{\prime} \simeq 4 \mathrm{mM}\right)$, but then the transport rate at physiological concentrations of $\mathrm{Na}^{+}$and $\mathrm{K}^{+}$ becomes unreasonably small. This discrepancy may result from the (probably unrealistic) assumption of identical and independent binding sides and/or from the fact that the enzymatic activity (Fig. 3) and the rate constants of Table 1 have been measured under different experimental conditions. In any case, as long as electrophysiological as well as biochemical data are not available for one and the same cell system, a strictly quantitative analysis of pump currents seems difficult. It will be shown below, however, that even with limited information on the

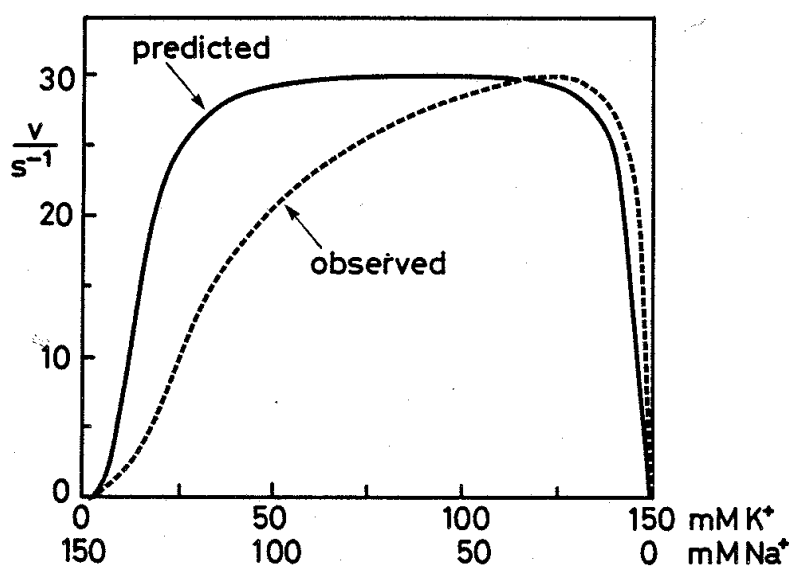

Fig. 3. Rate of ATP hydrolysis of Na,K-ATPase as a function of the molar fraction of $\mathrm{Na}^{+}$at a constant $\left(\mathrm{Na}^{+}+\mathrm{K}^{+}\right)$concentration of $150 \mathrm{mM}$. The theoretical curve has been calculated using the kinetic constants given in Table 1 . The experimental curve comes from an experiment with ox brain enzyme at $t=37^{\circ} \mathrm{C}, \mathrm{pH}=7.4$ and an ATP concentration of $3 \mathrm{mM}$ (Skou 1975, Fig. 1). The experimental curve has been normalized to give the same maximum value as the theoretical curve kinetic parameters, valuable insight into the nature of the charge-translocating steps can be obtained from current-voltage curves.

\section{Calculation of pump currents}

For the numerical evaluation of steady-state pump currents we introduce the fraction $x\left[A_{i}\right]$ of total enzyme present in state $A_{i}$. The quantities $x\left[A_{i}\right]$ can be obtained using the steady-state conditions $\mathrm{d}\left(x\left[A_{j}\right]\right) / \mathrm{d} t=0$. For instance, for species $\mathrm{E}_{2}\left(\mathrm{~K}_{2}\right)$ (Fig. 1) one has the equation:

$$
\begin{aligned}
q_{f} x\left[\mathrm{P}-\mathrm{E}_{2} \cdot \mathrm{K}_{2}\right] & +s_{b} x\left[\mathrm{ATP} \cdot \mathrm{E}_{2}\left(\mathrm{~K}_{2}\right)\right] \\
& -\left(q_{b} c_{P}+s_{f} c_{T}\right) x\left[\mathrm{E}_{2}\left(\mathrm{~K}_{2}\right)\right]=0 .
\end{aligned}
$$

Additional relations of the form of Eqs. (1)-(3) hold for the fast ion-binding reactions. From these equations, together with the condition that the sum of all $x\left[A_{i}\right]$ is unity, the steady-state values of the $x\left[A_{i}\right]$ are determined numerically using the matrix inversion method (Johnson 1980). The stationary rate, $v$, of ATP hydrolysis is then obtained as the difference of the forward and backward rates at any one of the steps of the reaction cycle, e.g.

$v=q_{f} x\left[\mathrm{P}-\mathrm{E}_{2} \cdot \mathrm{K}_{2}\right]-q_{b} c_{P} x\left[\mathrm{E}_{2}\left(\mathrm{~K}_{2}\right)\right]$.

Since the reaction scheme represented in Fig. 1 corresponds to a completely coupled operation mode of the pump, one net charge it translocated per hydrolyzed ATP so that the average current, $I$, per pump molecule is simply given by:

$I=e_{0} v$

( $e_{0}=1.6 \cdot 10^{-19} \mathrm{C}$ is the elementary charge).

\section{Current-voltage curves}

For a given set of rate constants the shape of the current-voltage curve may be expected to vary in a wide range, depending on the values of the dielectric coefficients $\alpha^{\prime}, \alpha^{\prime \prime}, \beta^{\prime}, \beta^{\prime}, \ldots$ which describe the voltage dependence of the kinetic parameters (Eqs. (7)-(13)). In the following we consider the currentvoltage behavior in a number of special situations differing in the voltage dependence of the individual reaction steps. In order to simplify the discussion, we assume that the position of the alkali-ion binding sites in the two "occluded" states $\left(\mathrm{Na}_{3}\right) \mathrm{E}_{1}-\mathrm{P}$ and ATP $\cdot E_{2}\left(K_{2}\right)$ is the same. This means that the binding sites move by the same distance in the transitions $\mathrm{Na}_{3} \cdot \mathrm{E}_{\mathrm{I}} \cdot \mathrm{ATP} \rightarrow\left(\mathrm{Na}_{3}\right) \mathrm{E}_{1}-\mathrm{P}$ and $\mathrm{K}_{2} \cdot \mathrm{E}_{1} \cdot \mathrm{ATP}$ $\rightarrow \mathrm{ATP} \cdot \mathrm{E}_{2}\left(\mathrm{~K}_{2}\right)$, so that $\beta^{\prime}=-\gamma^{\prime}$ and, correspondingly, $\beta^{\prime \prime}=-\gamma^{\prime \prime}$. We further assume, if not otherwise stated, that intrinsic charge displacements other 
than movements of charged ligand groups at the alkali-ion binding sites are negligibly small, so that $\eta^{\prime}=\eta^{\prime \prime}=\theta^{\prime}=\theta^{\prime \prime}=0$ (this restriction will be relaxed later).

\section{A) Low-field access channels; ion-binding constants voltage-independent}

An ion passing through the pump molecule in the membrane has to travel a distance of at least $4-5 \mathrm{~nm}$. It is unlikely that the ion binding sites move that far when the protein undergoes the transition from $E_{1}$ to $E_{2}$. For this reason it is usually assumed that the binding sites are connected with the aqueous phase by some sort of access channel (Tanford 1983). The access channel may be a narrow and relatively specific pathway in the protein allowing the passage of the transported ions but excluding other ion species. In this case (which will be discussed later) part of the transmembrane voltage drops across the length of the access channel, as it has been assumed in Fig. 2.

Another limiting case, which is considered in this section, is given when the access channel is a wide, water-filled pore with a low electrical resistance (Fig. 4). Under this condition the field strength in the access channel is always small so that almost all the voltage drops across the gating part of the pump molecule. Specifically, we assume in the following that the ion binding sites are located at the inner terminus of the access channel, so that $\alpha^{\prime}=\alpha^{\prime \prime}=0 \quad$ (Fig. 2). This means, according to Eqs. (7) and (8), that the equilibrium constants of ion binding become voltage-independent.

Alkali-ion binding sites negatively charged. When the ligand system bears three negative charges $\left(z_{L}=-3\right)$, the net charge of the alkali-ion binding sites is zero in state $\mathrm{Na}_{3} \cdot \mathrm{E}_{1} \cdot \mathrm{ATP}$ and -1 in state $\mathrm{P}-\mathrm{E}_{2} \cdot \mathrm{E}_{2}$. In Fig. 5 current-voltage curves under the condition $\alpha^{\prime}=\alpha^{\prime \prime}=\eta^{\prime}=\eta^{\prime \prime}=\theta^{\prime}=\theta^{\prime \prime}=0, z_{L}=-3$ are given for three different values of parameter $\beta^{\prime}=-\gamma^{\prime}$ representing the dielectric distance over which sodium ions move in the transition $\mathrm{Na}_{3} \cdot \mathrm{E}_{1} \cdot \mathrm{ATP}$ $\rightarrow\left(\mathrm{Na}_{3}\right) \mathrm{E}_{1}-\mathrm{P}$. (It should be noted that according to Eqs. (14) and (15) $\beta^{\prime \prime}$ is equal to $1-\beta^{\prime}$ and $\gamma^{\prime \prime}$ equal to $-\gamma^{\prime}-1$.) The current monotonically increases with voltage $V$ and reaches asymptotic values at $V \rightarrow \infty$ and $V \rightarrow-\infty$. For $\beta^{\prime}=0.5$ the limiting currents (referred to a single pump molecule) are $I(\infty)=13.5 \cdot 10^{-19} \mathrm{~A}$ and $I(-\infty)=-3.1 \cdot 10^{-19} \mathrm{~A}$.

The reversal potential $V_{0}$ at which the net pump current vanishes is given by the thermodynamic relation

$V_{0}=\frac{\Delta G}{F}+\frac{R T}{F}\left(3 \ln \frac{c_{N}^{\prime \prime}}{c_{N}^{\prime}}+2 \ln \frac{c_{K}^{\prime}}{c_{K}^{\prime \prime}}\right)$

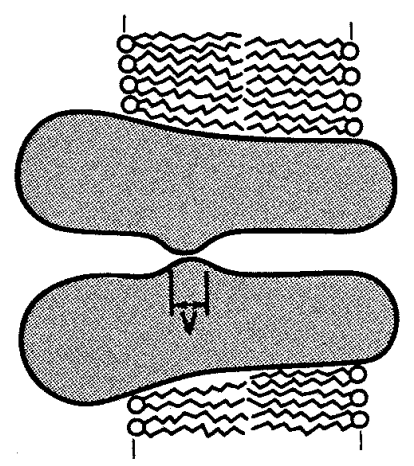

Fig. 4. Limiting case of a pump molecule with wide, waterfilled access channels having a low electrical resistance. The transmembrane voltage, $V$, drops across the gating part of the molecule

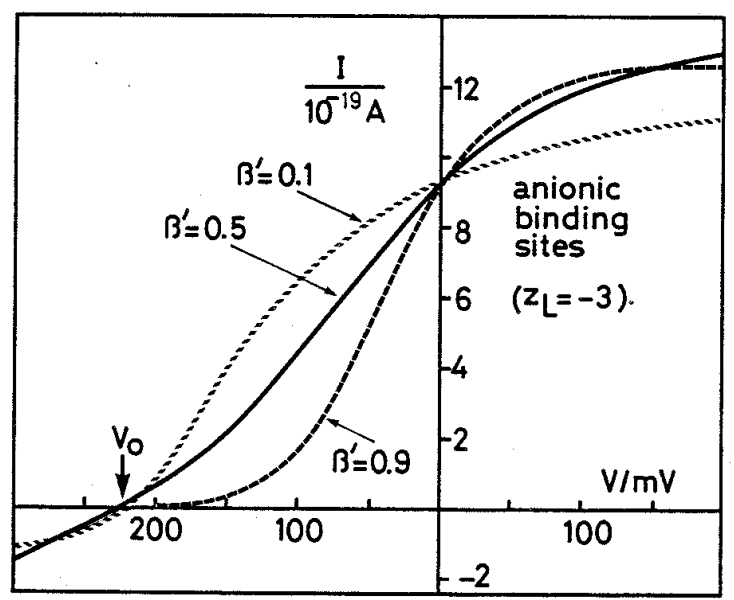

Fig. 5. Current-voltage curve of a pump molecule with lowresistance access channels and negatively charged ion-binding sites $\left(z_{L}=-3\right)$. The net charge of the binding site is zero in state $\mathrm{Na}_{3} \cdot \mathrm{E}_{1} \cdot \mathrm{ATP}$ and -1 in state $\mathrm{P}-\mathrm{E}_{2} \cdot \mathrm{K}_{2} . I$ is the pump current (referred to a single pump molecule), $V$ the transmembrane voltage and $V_{0}$ the reversal potential (Eq. (22)). The coefficient $\beta^{\prime}$ represents the dielectric distance over which sodium ions move in the transition $\mathrm{Na}_{3} \cdot \mathrm{E}_{1} \cdot \mathrm{ATP} \rightarrow\left(\mathrm{Na}_{3}\right) \mathrm{E}_{1}-\mathrm{P}$ (Fig. 2). For the calculation of $I(V)$ the values of the kinetic parameters given in Table 1 have been used, together with $\alpha^{\prime}=\alpha^{\prime \prime}=\eta^{\prime}=\eta^{\prime \prime}=\theta^{\prime}=\theta^{\prime \prime}=0$ and $\gamma^{\prime}=-\beta^{\prime}, \gamma^{\prime \prime}=-\beta^{\prime \prime}=\beta^{\prime}-1$

Implicit in the derivation of Eq. (22) is the validity of the reaction scheme of Fig. 1 which implies a fixed stoichiometry of $1 \mathrm{ATP}: 3 \mathrm{Na}^{+}: 2 \mathrm{~K}^{+}$. For the chosen set of parameters $(\Delta G=-58 \mathrm{~kJ} / \mathrm{mol}$, $T=25^{\circ} \mathrm{C}, c_{N}^{\prime}=10 \mathrm{~m} M, c_{N}^{\prime \prime}=140 \mathrm{~m} M, c_{K}^{\prime}=150 \mathrm{~m} M$, $\left.c_{K}^{\prime \prime}=5 \mathrm{~m} M\right), V_{0}$ is equal to $-223 \mathrm{mV}$.

The saturating behaviour of the current-voltage curve may be qualitatively understood in the following way. Under the conditions considered here $\left(\alpha^{\prime}=\alpha^{\prime \prime}=\eta^{\prime}=\eta^{\prime \prime}=\theta^{\prime}=\theta^{\prime \prime}=0, z_{L}=-3\right.$ ) the only voltage-dependent steps are the transitions $\mathrm{P}-\mathrm{E}_{2} \cdot \mathrm{K}_{2}$ $\rightarrow \mathrm{E}_{2}\left(\mathrm{~K}_{2}\right)$ and ATP $\cdot \mathrm{E}_{2}\left(\mathrm{~K}_{2}\right) \rightarrow \mathrm{K}_{2} \cdot \mathrm{E}_{1} \cdot \mathrm{ATP}$ which 
involve a movement of the $\mathrm{K}^{+}$-loaded binding sites (total charge $-e_{0}$ ) within the membrane dielectric. Thus, for increasing positive voltages $(V>0)$ the voltage-dependent transition rates in forward direction increase, until eventually the voltage-insensitive steps of the cycle become rate limiting. This means that for $V \rightarrow \infty$ (and also, by the same argument, for $V \rightarrow-\infty$ ) the current approaches an asymptotic value.

Qualitatively similar (saturating) current-voltage curves as those shown in Fig. 5 are obtained in the case of a ligand system with two negative charges. This has to be expected since for $z_{L}=-2$ the total charge of the binding site in the $E_{1} \rightarrow E_{2}$ transition is +1 and 0 in the $E_{2} \rightarrow E_{1}$ transition. A reaction model of the $\mathrm{Na}, \mathrm{K}$-pump with $z_{L}=-2$ has recently been proposed by Karlish et al. (1985).

Neutral alkali-ion binding sites. Current-voltage curves for the case where the ligand groups at the ion-binding sites are neutral are shown in Fig. 6. The pump current is large at membrane voltages, $V$, between -50 and $50 \mathrm{mV}$ but decreases steeply towards more positive and more negative values of $V$, approaching zero for both $V \rightarrow \infty$ and $V \rightarrow-\infty$ (a marginal minimum occurs at voltages below $V_{0}$ ). The shape of the $I(V)$ curves shown in Fig. 6 differs strongly from the saturating $I(V)$ characteristic in the previous case (Fig. 5). At positive voltages (and also at negative voltages below $\left.V_{0}\right)$ the $I(V)$ curve exhibits a region with negative pump conductance. The nonmonotonic behaviour of the current results from the fact that the potassium-loaded sites have a positive net charge when the ligands are neutral. Thus, when the binding sites move toward the cytoplasm in the

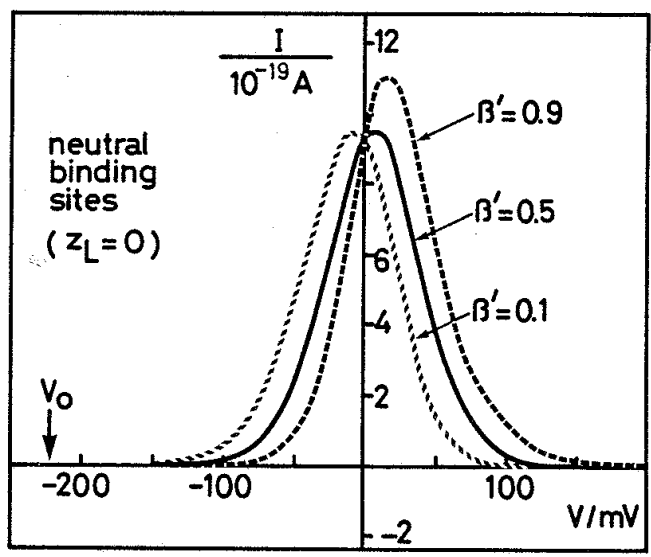

Fig. 6. Voltage dependence of pump current, $I$, under the same conditions as in Fig. 5, but with uncharged alkali-ion binding sites $\left(z_{L}=0\right)$. The net charge of the binding site is +3 in state $\mathrm{Na}_{3} \cdot \mathrm{E}_{1} \cdot \mathrm{ATP}$ and +2 in state $\mathrm{P}-\mathrm{E}_{2} \cdot \mathrm{K}_{2}$. All three curves go through a (marginal) minimum for $V<V_{0}$ and approach zero for $V \rightarrow-\infty$ transition $\mathrm{ATP} \cdot \mathrm{E}_{2}\left(\mathrm{~K}_{2}\right) \rightarrow \mathrm{K}_{2} \cdot \mathrm{E}_{1} \cdot \mathrm{ATP}$, net charge is moved against the direction of overall chargetranslocation. For increasing positive voltages $(V>0)$ the forward rate constant $k_{f}$ of the transition ATP $\cdot E_{2}\left(K_{2}\right) \rightarrow K_{2} \cdot E_{1} \cdot A T P$ decreases to zero so that the pump current vanishes. Conversely, at negative voltages at which the pump is driven in the backward direction, the rate constant $k_{b}$ becomes very small and the pump current again goes to zero. In the vicinity of the reversal potential, $V_{0}$, the slope of the $I(V)$ curve is rather small, meaning that pump reversal by hyperpolarisation would be difficult to detect under these conditions.

\section{B) High-field access channels ("ion wells"); voltage-dependent ion-binding constants}

In this section we consider the case that the ionbinding sites are located at the end of narrow access channels allowing the entry of $\mathrm{Na}^{+}$or $\mathrm{K}^{+}$, but not of other ions. Under this condition part of the applied voltage drops across the length of the access channels so that the equilibrium constants $\mathrm{K}_{N}^{\prime}, \mathrm{K}_{N}^{\prime \prime}, \mathrm{K}_{K}^{\prime}$ and $\mathrm{K}_{K}^{\prime \prime}$ of ion binding become voltage-dependent ("ionwell" behaviour). We specifically assume that translocations of the binding sites in the transitions to the occluded states are negligibly small, meaning that $\beta^{\prime}=\beta^{\prime \prime}=\gamma^{\prime}=\gamma^{\prime \prime}=0$ and $\alpha^{\prime}+\alpha^{\prime \prime}=1$. In this limiting case the voltage dependence of pump current is determined exclusively by the voltage dependence of the equilibrium constants $\mathrm{K}_{N}^{\prime}, \mathrm{K}_{N}^{\prime \prime}, \mathrm{K}_{K}^{\prime}$ and $\mathrm{K}_{K}^{\prime \prime}$. In Fig. 7 current-voltage curves are represented for three different values of the coefficient $\alpha^{\prime}$ describing the depth of the ion well at the cytoplasmic side (Fig. 2). For $\alpha^{\prime}=0$ and $\alpha^{\prime}=0.5$ the shape of $I(V)$ is similar to that in Fig. 6, i.e., the current goes through a maximum and vanishes at large positive voltages. This results from the presence of a "potassium well" at the extracellular side of the pump leading to a depopulation of state $\mathrm{P}-\mathrm{E}_{2} \cdot \mathrm{K}_{2}$ for $V \rightarrow \infty$. For $\alpha^{\prime}=1$, however, binding of $\mathrm{K}^{+}$in state $\mathrm{E}_{2}$ becomes voltage-independent so that $I(V)$ monotonically increases for $V>V_{0}$ towards a limiting current $\left(I(\infty) \simeq 3.0 \cdot 10^{-18} \mathrm{~A}\right)$.

In the presence of ion wells a voltage change has an analogous effect on the occupancy of the ionbinding sites as a change of external concentration. This leads to a pronounced voltage effect on the ion concentration dependence of pump activity. An example is shown in Fig. 8 in which the pump current is plotted as a function of extracellular $\mathrm{K}^{+}$ concentration, $c_{K}^{\prime \prime}$, for different membrane potentials, $V=\psi^{\prime}-\psi^{\prime \prime}$. It is seen that the apparent $\mathrm{K}_{M}$ values, i.e., the $\mathrm{K}^{+}$concentrations for half-maximum pump activation, strongly decrease with increasingly negative potentials, $V$. However, such a monotonic effect 


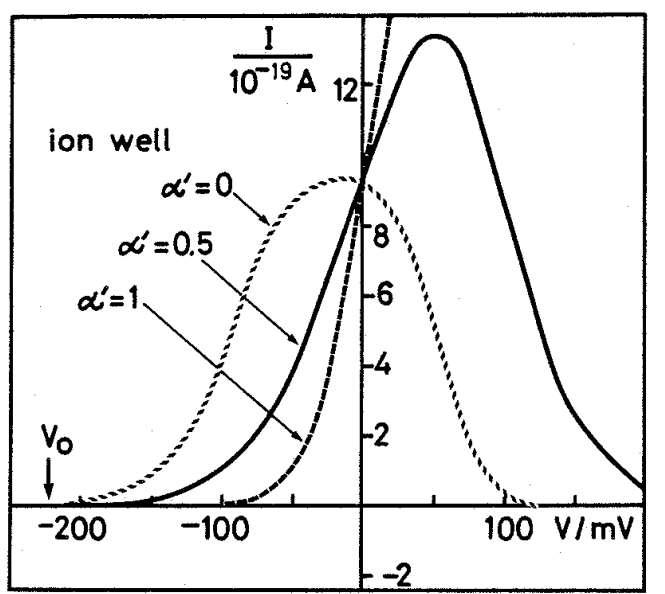

Fig. 7. Pump current, $I$, as a function of membrane potential under the assumption that the only voltage-dependent parameters are the equilibrium constants of ion binding (pure "ionwell" behaviour). The parameter $\alpha^{\prime}$ describes the depth of the ion well at the cytoplasmic site. For the calculation of $I(V)$ the values of the kinetic parameters given in Table 1 have been used together with $\beta^{\prime}=\beta^{\prime \prime}=\gamma^{\prime}=\gamma^{\prime \prime}=\eta^{\prime}=\eta^{\prime \prime}=\theta^{\prime}=\theta^{\prime \prime}=0$ and $\alpha^{\prime \prime}=1-\alpha^{\prime}$. For $\alpha^{\prime}=1$ the pump current approaches a limiting value $I(\infty) \simeq 3.0 \cdot 10^{-18} \mathrm{~A}$ at large positive voltages

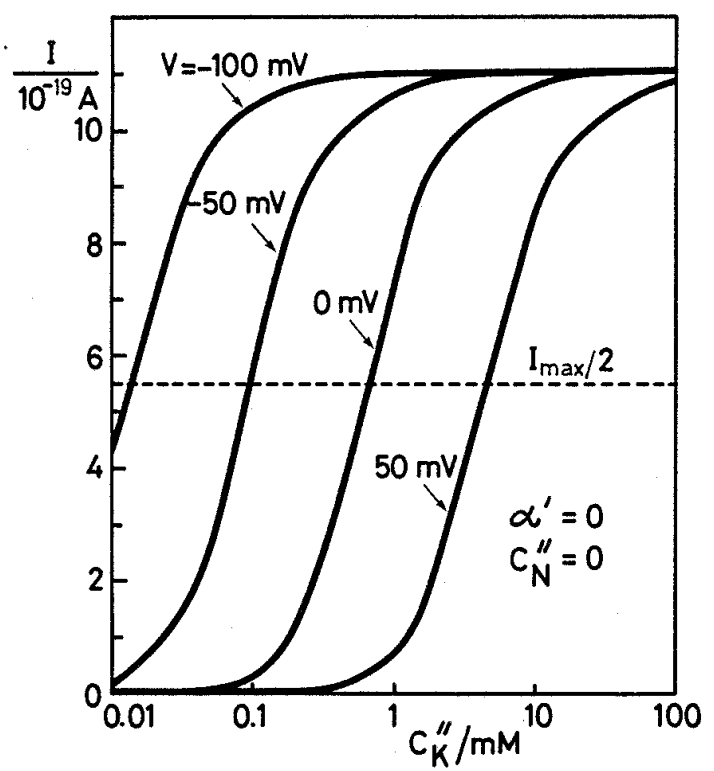

Fig. 8. Pump current as a function of extracellular potassium concentration, $c_{K}^{\prime \prime}$, for different membrane potentials. The kinetic parameters are the same as in Fig. 7, except for $\alpha^{\prime}=0$ and $c_{N}^{\prime \prime}=0$. Under the condition $\alpha^{\prime}=0$ the entire voltage drops between the potassium binding sites (state $E_{2}$ ) and the extracellular solution

of voltage on $\mathrm{K}_{M}$ is observed only in the absence of extracellular sodium $\left(c_{N}^{\prime \prime}=0\right)$; for $c_{N}^{\prime \prime}>0$ the voltage dependence of $I\left(c_{K}^{\prime \prime}\right)$ becomes more complicated since in this case the membrane voltage affects the competition between $\mathrm{Na}^{+}$and $\mathrm{K}^{+}$for the extracellular binding sites.

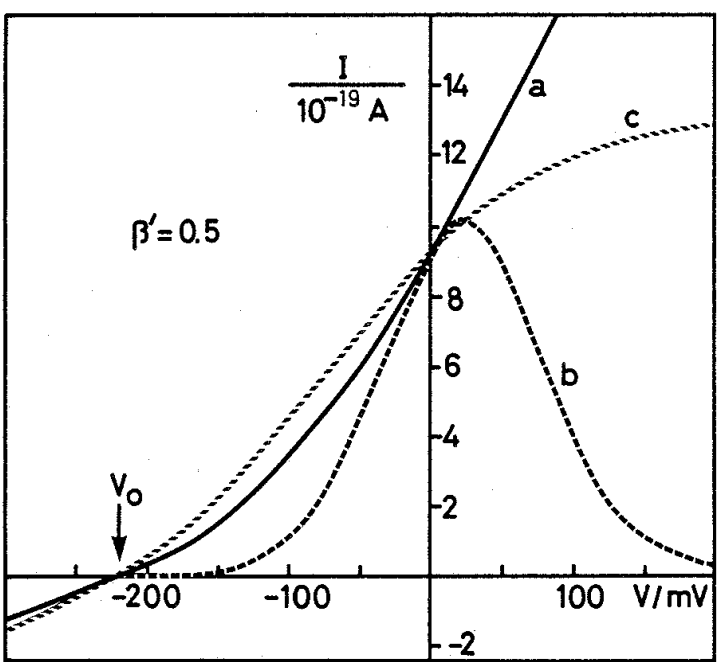

Fig. 9. Effect of intrinsic charge displacements in the protein on the $I(V)$ characteristic. Except for the values of $\eta^{\prime}, \eta^{\prime \prime}, \theta^{\prime}$ and $\theta^{\prime \prime}$, the same parameters were used as for the calculation of the curve labelled " $\beta$ ' $=0.5$ " in Fig. 5. Curve a: $\eta^{\prime}=\eta^{\prime \prime}=-\theta^{\prime}$ $=-\theta^{\prime \prime}=0.25$ (superlinear behaviour); curve $b: \eta^{\prime}=\eta^{\prime \prime}=-\theta^{\prime}$ $=-\theta^{\prime \prime}=1$ (inactivation); curve c: $\eta^{\prime}=\eta^{\prime \prime}=\theta^{\prime}=\theta^{\prime \prime}=0$ (saturating behaviour). Curve $c$ has been reproduced from Fig. 5 for comparison

\section{C) Intrinsic charge-displacements}

In the course of a conformational transition intrinsic charges of the protein other than ligand charges or charges of the transported ions may be displaced, for instance by rotation of dipolar amino-acid residues or by rearrangement of salt bridges (Karlish et al. 1985). In this case some (or all) of the coefficients $\eta^{\prime}$, $\eta^{\prime \prime}, \theta^{\prime}$ and $\theta^{\prime \prime}$ may assume non-zero values. This increases the range of possible shapes of current-voltage curves considerably. In the following we consider two special situations in which the $I(V)$ curve is strongly affected by intrinsic charge movements:

Superlinear current-voltage behaviour. For given values of $z_{L}, \beta^{\prime}, \beta^{\prime \prime}, \gamma^{\prime}$ and $\gamma^{\prime \prime}$ the coefficients $\eta^{\prime}, \eta^{\prime \prime}, \theta^{\prime}$ and $\theta^{\prime \prime}$ may be chosen in such a way that all forward rate constants $\left(p_{f}, l_{f}, q_{f}\right.$ and $\left.k_{f}\right)$ increase and all backward rate constants $\left(p_{b}, l_{b}, q_{b}\right.$ and $\left.k_{b}\right)$ decrease with increasing voltage, $V$ (compare Eqs. (9)-(13)). In this case the $I(V)$ curve exhibits a superlinear behaviour, i.e., the current increases more steeply than voltage. Under conditions as in Fig. $5\left(z_{L}=-3, \beta^{\prime}=\beta^{\prime \prime}\right.$ $=-\gamma^{\prime}=-\gamma^{\prime \prime}=0.5$ ) this occurs, e.g., for $\eta^{\prime}=\eta^{\prime \prime}$ $=-\theta^{\prime}=-\theta^{\prime \prime}=0.25$. The $I(V)$ curve calculated for these parameter values is shown in Fig. 9 (curve a).

Inactivation. When the reactions $\mathrm{Na}_{3} \cdot \mathrm{E}_{1} \cdot \mathrm{ATP} \rightarrow$ $\left(\mathrm{Na}_{3}\right) \mathrm{E}_{1}-\mathrm{P} \rightarrow \mathrm{P}-\mathrm{E}_{2} \cdot \mathrm{Na}_{3}$ are associated with large intrinsic charge-displacements $\left(\eta^{\prime}+\eta^{\prime \prime} \gtrsim 1\right)$, the transition $E_{1} \rightarrow E_{2}$ will be strongly favoured over the 
back transition $E_{2} \rightarrow E_{1}$ in the presence of a positive membrane potential $(V>0)$. Under this condition the pumping cycle becomes blocked since most pump molecules will stay in state $E_{2}$. This is illustrated by curve $b$ of Fig. 9 which has been calculated with $\eta^{\prime}=\eta^{\prime \prime}=-\theta^{\prime}=-\theta^{\prime \prime}=1$. At voltages above $50 \mathrm{mV}$ the pump current steeply decreases towards zero. Thus, the interaction of intrinsic charges with a transmembrane electric field represents a mechanism by which the activity of a pump may be regulated. Whether such a mechanism is operative in the case of the $\mathrm{Na}, \mathrm{K}$-pump is not known so far.

\section{Comparison with experimental results}

In a recent paper, Gadsby et al. (1985) described whole-cell patch-clamp experiments with isolated heart cells in which the pump current was determined as the difference of total membrane current in the absence and in the presence of ouabain. In the experimental voltage range $(-140 \mathrm{mV}$ to $+60 \mathrm{mV})$ the current increased monotonically from very small positive values at $-140 \mathrm{mV}$, exhibiting a saturating behaviour above $-50 \mathrm{mV}$ (Fig. 10). Under the conditions of the experiment $\left(c_{N}^{\prime}=34 \mathrm{~m} M, c_{K}^{\prime}=110 \mathrm{~m} M\right.$, $\left.c_{N}^{\prime \prime}=144 \mathrm{~m} M, \quad c_{K}^{\prime \prime}=6.4 \mathrm{~m} M\right)$ and assuming a $\Delta G$ value of $-58 \mathrm{~kJ} / \mathrm{mol}$ as before, the reversal potential $V_{0}$ is estimated from Eq. (22) to be about $-340 \mathrm{mV}$. (Since the $\mathrm{Na}, \mathrm{K}$ pump discriminates poorly between $\mathrm{K}^{+}$and $\mathrm{Cs}^{+}$(Sachs 1977), $c_{K}^{\prime}$ and $c_{K}^{\prime \prime}$ have been taken as the sum of the $\mathrm{K}^{+}$and $\mathrm{Cs}^{+}$concentrations used in the experiment). This value of $V_{0}$ is much larger (in

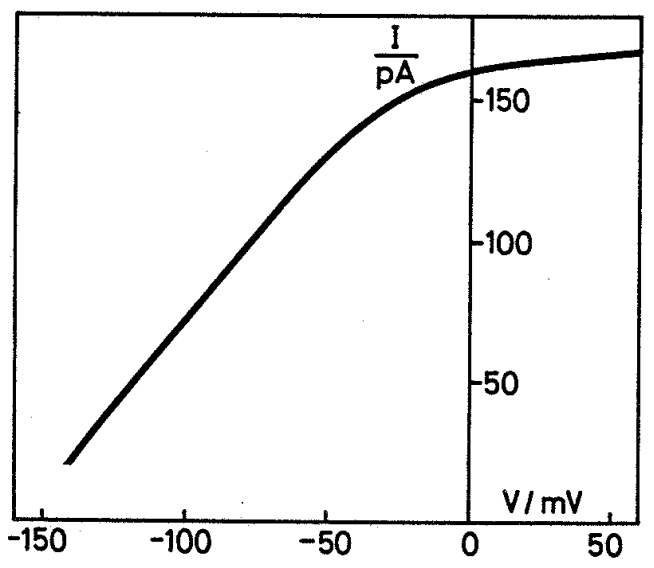

Fig. 10. Current-voltage characteristic of the Na, K-pump of isolated heart cells (Gadsby et al. 1985). The cell interior was perfused with $34 \mathrm{~m} M \mathrm{Na}^{+}, 10 \mathrm{~m} M \mathrm{~K}^{+}, 100 \mathrm{~m} M \mathrm{Cs}^{+}$and $10 \mathrm{~m} M$ ATP; the extracellular medium contained $144 \mathrm{mM} \mathrm{Na}{ }^{+}$, $5.4 \mathrm{mM} \mathrm{K}^{+}$and $1 \mathrm{~m} M \mathrm{Cs}^{+} . I$ is the ouabain-sensitive component of the membrane current of a single cell. Redrawn from Fig. 2 of Gadsby et al. (1985) absolute magnitude) than the reversal potential estimated by extrapolation of the experimental $I(V)$ curve to $I=0\left(V_{0} \simeq-160 \mathrm{mV}\right)$. This discrepancy may result from a $\mathrm{Na}^{+}: \mathrm{K}^{+}$coupling ratio which is different from 3:2 (Anner and Moosmayer 1982; Glynn 1984; Blostein 1985) and/or from incomplete coupling between ATP hydrolysis and transport (Navarro and Essig 1984).

Another possible origin of the discrepancy is the shape of the $I(V)$ curve itself. As seen in Figs. 5, 6,7 and 9 , for certain parameter values the pump current may approach the reversal potential with a very small slope. This means that linear extrapolation to $I=0$ may lead to a large error in $V_{0}$. The experimental $I(V)$ curve has a similar shape as the curve with $\beta^{\prime}=0.9$ in Fig. 5. No attempt has been made, however, to fit a theoretical curve to the experimental results, since with the limited experimental information available at present the choice of possible parameter values is not unique. A more reliable estimate of kinetic parameters should be possible as soon as $I(V)$ data at different alkali-ion concentrations and in a more extended voltage range will become available.

In earlier studies with nerve axons (Marmor 1971; Thomas 1972; Brinley and Mullins 1974; Abercrombie and De Weer 1978), cardiac preparations (Isenberg and Trautwein 1974; Eisner and Lederer 1980; Gadsby 1984) and other muscle cells (Lederer and Nelson 1984) a voltage dependence of pump current has never been observed. As discussed by Gadsby et al. (1985), reasons for this failure may be the limited experimental voltage range and/or the difficulty in separating pump currents from other current components. It is feasible, however, that in a certain voltage range (say, -90 to $-20 \mathrm{mV}$ ) the $\mathrm{Na}, \mathrm{K}$ pump acts as a constant-current source. As discussed above, such a saturating behaviour is always observed when a voltage-independent reaction step becomes rate limiting. Under the conditions of Fig. 5 saturation occurs at $V>0$, but for other values of the rate constants the saturating part of $I(V)$ may extend toward negative voltages.

Voltage effects on the $\mathrm{Na}, \mathrm{K}$-pump reconstituted in artificial lipid vesicles have recently been described by Karlish et al. (1985). They observed that the rate of ATP-driven sodium flux was increased when the potential of the "cytoplasmic" side was made positive. The voltage effect disappeared at low ATP concentrations at which the $E_{2}\left(K_{2}\right) \rightarrow E_{1} \cdot K_{2}$ transition becomes rate limiting. As an explanation of this finding the authors proposed that the ligand system bears two negative charges $\left(z_{L}=-2\right)$. This would mean (if intrinsic charge-translocations are excluded) that the $\mathrm{E}_{2}\left(\mathrm{~K}_{2}\right) \rightarrow \mathrm{E}_{1} \cdot \mathrm{K}_{2}$ transition is voltage-independent. 


\section{Pump reversal}

In the absence of intracellular ATP and in the presence of large concentration gradients for $\mathrm{Na}^{+}$ and $\mathrm{K}^{+}$the $\mathrm{Na}, \mathrm{K}$-pump runs backward, synthesizing ATP from ADP and $\mathrm{P}_{i}$ (Garrahan and Glynn 1967). De Weer and Rakowski (1984) have recently studied pump currents in squid axons under conditions of pump reversal. At nominal zero intracellular ATP concentration and finite concentrations of ADP and $\mathrm{P}_{i}$ they observed a pump-specific current which was directed inward, opposite to the direction of pump current under physiological conditions. Contrary to simple expectation, the absolute magnitude of the inward current decreased when the axon interior was made more negative. On the basis of the foregoing discussion this observation of a negative pump conductance can be explained by assuming that in at least one of the reaction steps net charge is moved against the direction of overall charge-translocation. This is the case, for instance, when the ligand groups of the alkali-ion binding sites are neutral (Fig. 6) so that the $\mathrm{K}^{+}$-loaded sites are positively charged. Under this condition hyperpolarization has an inhibitory effect when in the transition $\mathrm{K}_{2} \cdot \mathrm{E}_{1} \cdot \mathrm{ATP} \rightarrow$ ATP $\cdot E_{2}\left(K_{2}\right)$ the binding sites move outward. Current-voltage curves for this case under conditions of pump reversal are shown in Fig. 11. It is seen that the pump exhibits a negative differential conductance at sufficiently negative membrane potentials. Thus, the voltage dependence of reverse pumpcurrent observed by De Weer and Rakowski (1984) can be understood on the basis of charge displacements associated with individual reaction steps of the cycle. As discussed above, this model also implies that in the forward-running mode of the

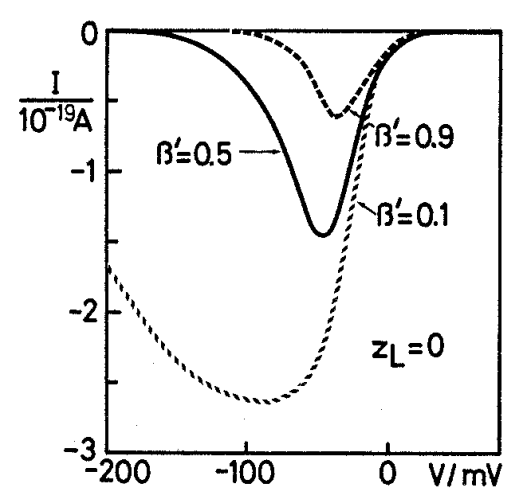

Fig. 11. Current-voltage characteristic of the pump running backward. The pump current, $I$, has been calculated using the same kinetic parameters as in Fig. 6, but for the conditions of the experiment of De Weer and Rakowski (1984) $\left(c_{N}^{\prime} \approx 0\right.$, $c_{N}^{\prime \prime}=435 \mathrm{~m} M, c_{K}^{\prime}=300 \mathrm{~m} M, c_{K}^{\prime \prime} \approx 0, \Delta G \approx 0, \tilde{s}_{f} c_{T} \approx 0$ ). The pump exhibits a negative differential conductance at strongly hyperpolarizing voltages pump a region of negative conductance occurs at more positive potentials (Fig.6). However, the negative-conductance region in the forward mode may lie outside the experimentally accessible voltage range. While the explanation for the negative conductance discussed here is attractive for its simplicity, other possibilities cannot be excluded at present, for instance the existence of a voltage-sensitive gate operating in series with the pump (De Weer 1984; De Weer and Rakowski 1984).

\section{Discussion}

The treatment of current-voltage behaviour of the $\mathrm{Na}, \mathrm{K}$-pump given above has been based on the assumption that the reaction pathway of the pump can be described as a sequence of transitions between discrete molecular states. The voltage dependence of the transition rate constant is determined by the corresponding charge displacements. Charge movement may result from migration of alkali ions in the access channels, from translocations of the ionbinding site, as well as from rotations of dipolar groups in the protein.

In the Post-Albers reaction scheme which has been used for the evaluation of transport rates, the $\mathrm{Na}: \mathrm{K}$ ratio has a fixed value of $3: 2$. In reality, the $\mathrm{Na}: \mathrm{K}$ coupling ratio (and also the $\mathrm{Na}$ : ATP ratio) may vary, depending on voltage and on the alkaliion concentrations. It is feasible, for instance, that in addition to the sequence $\mathrm{Na}_{3} \cdot \mathrm{E}_{1} \cdot \mathrm{ATP} \rightarrow$ $\left(\mathrm{Na}_{3}\right) \mathrm{E}_{1}-\mathrm{P} \rightarrow \mathrm{P}-\mathrm{E}_{2} \cdot \mathrm{Na}_{3}$ a parallel pathway exists in which the $E_{1} / E_{2}$ transition takes place with only two sodium ions bound to the binding site. Since the charge translocated in the two parallel pathways is different, the $\mathrm{Na}: \mathrm{K}$ coupling ratio will become voltage dependent. The treatment of $I(\mathrm{~V})$ behaviour may be easily extended to account for additional pathways in the reaction scheme.

The main information which is obtained from the experimental $I(V)$ curves is contained in the dielectric coefficients $\alpha^{\prime}, \alpha^{\prime \prime}, \beta^{\prime}, \ldots$ describing the charge translocations associated with the transitions in the reaction cycle (Eqs. (7)-(13)). An inherent complication in the analysis of experimental $I(V)$ curves results from the fact that several transitions in the reaction cycle may be voltage-dependent. If only limited experimental data are available, the evaluation of kinetic parameters from $I(V)$ curves may become ambiguous. It is therefore important to measure the $I(V)$ characteristic at different concentrations of ATP, ADP, $\mathrm{P}_{i}$ and of $\mathrm{Na}^{+}$and $\mathrm{K}^{+}$(Glynn 1984). The model may be further tested by studying the voltage dependence of the partial reactions of the pumping cycle, such as $\mathrm{Na}, \mathrm{Na}-$ or $\mathrm{K}, \mathrm{K}$-exchange (Cantley 1981). 
Acknowledgements. The authors wish to thank Drs. M. T. Nelson, J. A. Reynolds and Ch. Tanford for interesting discussions and Dr. M. T. Nelson for critically reading the manuscript. This work has been financially supported by Deutsche Forschungsgemeinschaft (Sonderforschungsbereich 156).

\section{Appendix A}

\section{Derivation of $E q .(4)$}

We consider an equilibrium situation in which the chemical driving force is exactly balanced by the electric and osmotic gradients (Tanford 1981):

$\exp (-\Delta G / R T)=\left(\frac{c_{N}^{\prime \prime}}{c_{N}^{\prime}}\right)^{3}\left(\frac{c_{K}^{\prime}}{c_{K}^{\prime \prime}}\right)^{2} \exp \left(-u_{0}\right)$

$c_{N}^{\prime}$ and $c_{K}^{\prime}$ are the $\mathrm{Na}^{+}$and $\mathrm{K}^{+}$concentrations on the cytoplasmic side and $c_{N}^{\prime \prime}$ and $c_{K}^{\prime \prime}$ are the concentrations at the extracellular side. The equilibrium voltage $u_{0}$ is defined according to Eq. (6). We further introduce the fraction $x[A]$ of enzyme present in state $A$. Under equilibrium conditions the ratio $x[A] / x[B]$ for each step of the cycle is equal to the ratio of the corresponding rate constants; for instance:

$\frac{x\left[\mathrm{E}_{2}\left(\mathrm{~K}_{2}\right)\right]}{x\left[\mathrm{P}-\mathrm{E}_{2} \cdot \mathrm{K}_{2}\right]}=\frac{q_{f}}{q_{b} c_{P}}$

(Fig. 1). Multiplication of the left-hand sides of all equations of type A.2 yields, together with Eq. (A.1):

$$
\begin{aligned}
1= & \frac{p_{f} l_{f} q_{f} s_{f} c_{T} k_{f}}{p_{b} c_{D} k_{b} s_{b} q_{b} c_{P} l_{b}} \cdot \frac{\mathrm{K}_{N 1}^{\prime \prime} \mathrm{K}_{N 2}^{\prime \prime} \mathrm{K}_{N 3}^{\prime \prime}}{\mathrm{K}_{N 1}^{\prime} \mathrm{K}_{N 2}^{\prime} \mathrm{K}_{N 3}^{\prime}} \cdot \frac{\mathrm{K}_{K 1}^{\prime} \mathrm{K}_{K 2}^{\prime}}{\mathrm{K}_{K 1}^{\prime \prime} \mathrm{K}_{K 2}^{\prime \prime}} \\
& \cdot \exp \left(-u_{0}+\Delta G / R T\right)
\end{aligned}
$$

(Läuger 1984). Since any voltage, $u$, can be obtained by a suitable choice of $c_{N}^{\prime}, c_{N}^{\prime \prime}, c_{K}^{\prime}, c_{K}^{\prime \prime}$, and since the rate constants do not explicitly depend on the ion concentrations, Eq. (A.3) holds for any voltage, $u$. This proves Eq. (4).

\section{References}

Abercrombie R, De Weer P (1978) Electric current generated by squid giant axon: external $\mathrm{K}$ and internal $\mathrm{ADP}$ effects. Am J Physiol 235: C63-68

Anner BM, Mossmayer M (1982) On the kinetics of the $\mathrm{Na}: \mathrm{K}$ exchange in the initial and final phase of sodium pump activity in liposomes. J Membr Sci 11:27-37

Blostein R (1985) Proton-activated rubidium transport catalyzed by the sodium pump. J Biol Chem 260:829-833

Brinley FJ, Mullins LJ (1974) Effects of membrane poential on sodium and potassium fluxes in squid axons. Ann NY Acad Sci 242:406-433

Cantley LC (1981) Structure and mechanism of the (Na,K)ATPase. Curr Top Bioenerg 11:201-237
Cantley LC, Carilli CT, Smith RL, Perlman D (1984) Conformational changes of $\mathrm{Na}$, KnATPase necessary for transport. Curr Top Membr Transp 19:315-322

Chapman JB, Johnson EA, Kootsey JM (1983) Electrical and biochemical properties of an enzyme model of the sodium pump. J Membr Biol 74:139-153

De Weer P (1984) Electrogenic pumps: theoretical and practical considerations. In: Blaustein MP, Lieberman M (eds) Electrogenic transport: Fundamental principles and physiological implications. Raven Press, New York, pp $1-15$

De Weer P, Rakowski RF (1984) Current generated by backward-running electrogenic Na pump in squid giant axons. Nature 309:450-452

Eigen M, Maass G (1966) Über die Kinetik der Metallkomplexbildung der Alkali- und Erdalkaliionen in wäßrigen Lösungen. Z Phys Chem 49:163-177

Eisner DA, Lederer WJ (1980) Characterization of the electrogenic sodium pump in cardiac Purkinje fibres. J Physiol (Lond) 303:441-474

Gadsby DC (1984) The Na/K pump of cardiac cells. Annu Rev Biophys Bioeng 13:373-398

Gadsby DC, Kimura J, Noma A (1985) Voltage dependence of $\mathrm{Na} / \mathrm{K}$ pump current in isolated heart cells. Nature 315:63-65

Garay RP, Garrahan PJ (1973) The interaction of sodium and potassium with the sodium pump in red cells. J Physiol (Lond) 231:297-325

Garrahan PJ, Glynn IM (1967) The incorporation of inorganic phosphate into adenosine triphosphate by reversal of the sodium pump. J Physiol (Lond) 192:237-256

Glasstone S, Laidler KJ, Eyring H (1941) The theory of rate processes. McGraw-Hill, New York

Glitsch HG, Pusch H, Schumacher T, Verdonck F (1982) An identification of the $\mathrm{K}$ activated Na pump current in sheep Purkinje fibres. Pflügers Arch 394:256-263

Glynn IM (1984) The electrogenic sodium pump. In: Blaustein MP, Lieberman M (eds) Electrogenic transport: Fundamental principles and physiological implications. Raven Press, New York, pp 33-48

Glynn IM, Richards DE (1982) Occlusion of rubidium ions by the sodium-potassium pum: its implications for the mechanism of potassium transport. J Physiol (Lond) 330: $17-43$

Glynn IM, Hara Y, Richards DE (1984) The occlusion of sodium ions within the mammalian sodium-potassium pump: its role in sodium transport. J Physiol (Lond) 351: $531-547$

Gradmann D, Hansen U-P, Slayman CL (1982) Reaction kinetic analysis of current-voltage relationships for electrogenic pumps in Neurospora and Acetabularia. Curr Top Membr Transp 16:257-276

Hansen U.P, Gradmann D, Sanders D, Slayman CL (1981) Interpretation of current-voltage relationship for "active" ion transport systems: I. Steady-state reaction-kinetic analysis of class-I mechanisms. J Membr Biol 63:165-190

Hastings DF, Skou JC (1980) Potassium binding to the $\left(\mathrm{Na}^{+}+\mathrm{K}^{+}\right)$-ATPase. Biochim Biophys Acta 601:380-385

Hodgkin AL, Keynes RD (1955) Active transport of cations in giant axons from Sepia and Loligo. J Physiol (Lond) 128: $26-60$

Isenberg $\mathrm{G}$, Trautwein W (1974) The effect of dihydroouabain and lithium-ions on the outward current in cardiac Purkinje fibers. Pflügers Arch 350:41-54

Johnson KJ (1980) Numerical methods in chemistry. Marcel Dekker, New York

Jørgensen PL (1982) Mechanism of the $\mathrm{Na}^{+}, \mathrm{K}^{+}$pump. Protein structure and conformations of the pure $\left(\mathrm{Na}^{+}+\mathrm{K}^{+}\right)$ATPase. Biochim Biophys Acta 694:27-68 
Kaniike, K, Lindenmayer GE, Wallick ET, Lane LK, Schwartz A (1976) Specific sodium binding to a purified sodium + potassium adenosine triphosphatase. Inhibition by ouabain. J Biol Chem 251:4794-4795

Karlish SJD (1980) Characterization of conformational changes in $(\mathrm{Na}, \mathrm{K})$ ATPase labeled with fluorescein at the active site. J Bioenerg Biomembr 12:111-136

Karlish SJD, Yates DW (1978) Tryptophan fluorescence of $\left(\mathrm{Na}^{+}+\mathrm{K}^{+}\right)$-ATPase as a tool for study of the enzyme mechanism. Biochim Biophys Acta 527:115-130

Karlish SJD, Stein WD (1985) Cation activation of the pig kidney sodium pump: Transmembrane allosteric effects of sodium. J Physiol (Lond) 359:119-149

Karlish SJD, Lieb WR, Stein WD (1982) Combined effects of ATP and phosphate on rubidium exchange mediated by $\mathrm{Na}, \mathrm{K}$-ATPase reconstituted into phospholipid vesicles. J Physiol (Lond) 328:333-350

Karlish SJD, Rephaeli A, Stein WD (1985) Transmembrane modulation of cation transport by the Na, K-pump. In: Glynn I, Ellory C (eds) The sodium pump. Company of Biologists, Cambridge, England, pp 487-499

Lambert JDC, Kerkut DA, Walker RJ (1974) The electrogenic sodium pump and membrane potential of identified neurones in Helix aspera. Comp Biochem Physiol 47A: $897-916$

Läuger P (1984) Thermodynamic and kinetic properties of electrogenic ion pumps. Biochim Biophys Acta 779: 307-341

Lafaire AV, Schwarz W (1985) Voltage-dependent ouabainsensitive current in the membrane of oocytes of Xenopus laevis. In: Glynn I, Ellory C (eds) The sodium pump. Company of Biologists, Cambridge, England, pp 523-525

Lederer WJ, Nelson MT (1984) Sodium pump stoichiometry determined by simultaneous measurements of sodium efflux and membrane current in barnacle. J Physiol (Lond) 348:665-677

Mårdh S (1975) Bovine brain $\mathrm{Na}^{+}, \mathrm{K}^{+}$-stimulated ATP phosphohydrolase studied by a rapid-mixing technique. $\mathrm{K}^{+}$stimulated liberation of $\left[{ }^{32} \mathrm{P}\right]$ orthophosphate from $\left[{ }^{32} \mathrm{P}\right]$ phosphoenzyme and resolution of the dephosphorylation into two phases. Biochim Biophys Acta 391:448-463

Mảrdh S, Zetterquist Ö (1974) Phosphorylation and dephosphorylation reactions of bovine brain $\left(\mathrm{Na}^{+}+\mathrm{K}^{+}\right)$-stimulated ATP phosphohydrolase studied by a rapid-mixing technique. Biochim Biophys Acta 350:473-483

Marmor MF (1971) The independence of electrogenic sodium transport and membrane potential in a molluscan neurone. J Physiol (Lond) 218:599-608

Matsui H, Hayashi Y, Homareda H, Kimura M (1977) Ouabain-sensitive ${ }^{42} \mathrm{~K}$ binding to $\mathrm{Na}^{+}, \mathrm{K}^{+}$-ATPase purified from canine kidney outer medulla. Biochem Biophys Res Commun 75: 373-380

Meunier JM, Tauc L (1970) Participation d'une pompe métabolique au potential de repos de neurones d'aplysie. J Physiol (Paris) 62:192c-193c

Mitchell P, Moyle J (1974) The mechanism of proton translocation in reversible proton-translocating adenosine triphosphatases. Biochem Soc (Spec Publ) 4:91-111

Moczydlowski EG, Fortes PAG (1981) Inhibition of sodium and potassium adenosine triphosphatase by $2^{\prime}, 3^{\prime}-0$ (2,4,6-trinitrocyclohexadienylidene) a denine nucleotides. J Biol Chem 256:2357-2366
Mullins LJ (1981) Ion transport in heart. Raven Press, New York

Nakashima S, Takahashi K (1966) Post-tetanic hyperpolarization and electrogenic Na pump in stretch receptor neuron of crayfish. J Physiol (Lond) 187:105-127

Navarro J, Essig A (1984) Voltage-dependence of $\mathrm{Ca}^{2+}$ uptake and ATP hydrolysis of reconstituted $\mathrm{Ca}^{2+}$-ATPase vesicles. Biophys J 46:709-717

Parlin RB, Eyring H (1954) Membrane permeability and electrical potential. In: Clarke HT (ed) Ion transport across membranes. Academic Press, New York, pp 103-118

Post RL, Sen AK, Rosenthal AS (1965) A phosphorylated intermediate in adenosine-triphosphate-dependent sodium and potassium transport across kidney membranes. J Biol Chem 240: 1437-1444

Reynolds JA, Johnson EA, Tanford C (1985) Application of the principle of linked functions to ATP-driven ion pumps: kinetics of activation by ATP. Proc Natl Acad Sci USA $82: 3658-3661$

Robinson JD (1983) Kinetic analyses and reaction mechanism of the Na,K-ATPase. Curr Top Membr Transp 19: $485-512$

Robinson JD, Flashner MS (1979) The $\left(\mathrm{Na}^{+}+\mathrm{K}^{+}\right)$-activated ATPase. Enzymatic and transport properties. Biochim Biophys Acta 549:145-176

Sachs JR (1977) Kinetic evaluation of the Na-K pump reaction mechanism. J Physiol (Lond) 273:489-514

Schuurmans Stekhoven F, Bonting SL (1981) Transport adenosine triphosphatases: Properties and functions. Physiol Rev 61:1-76

Skou JC (1975) The $\left(\mathrm{Na}^{+}+\mathrm{K}^{+}\right)$-activated enzyme system and its relationship to transport of sodium and potassium. Q Rev Biophys 7:401-434

Tanford C (1961) Physical chemistry of macromolecules, Chap. 8. John Wiley \& Sons, New York

Tanford C (1981) Equilibrium state of ATP-driven ion pumps in relation to physiological ion concentration gradients. J Gen Physiol 77:223-229

Tanford C (1983) Mechanism of free energy coupling in active transport. Annu Rev Biochem 52:379-409

Thomas RC (1972) Electrogenic sodium pump in nerve and muscle cells. Physiol Rev 52:563-594

Veech RL, Lawson JWR, Cornell NW, Krebs HA (1979) Cytosolic phosphorylation potential. J Biol Chem 254: $6538-6547$

Warshel A, Russel ST (1984) Calculations of electrostatic interactions in biological systems and in solutions. Qu Rev Biophys 17:283-422

Yamaguchi M, Sakamoto J, Tonomura Y (1983) Binding of monovalent cations to the Na, K-ATPase. Curr Top Membr Transp 19:203-217

Zade-Oppen AMM, Schooler JM, Cook P, Tosteson DC (1979) Effect of membrane potential and internal $\mathrm{pH}$ on active sodium-potassium transport and on ATP content in high-potassium sheep erythrocytes. Biochim Biophys Acta 555:285-298

Note added in proof: In a recent paper, Lafaire and Schwarz (1985) reported that the ouabain-sensitive membrane current of Xenopus oocytes exhibits a region of negative voltagedependence similar as in Fig. 6. 